\title{
Tryptanthrin derivatives as efficient singlet oxygen sensitizers
}

\author{
Daniela Pinheiro $^{1} \cdot$ Marta Pineiro $^{1} \cdot$ J. Sérgio Seixas de Melo ${ }^{1}(1)$
}

Received: 24 June 2021 / Accepted: 14 October 2021 / Published online: 4 November 2021

(c) The Author(s), under exclusive licence to European Photochemistry Association, European Society for Photobiology 2021

\begin{abstract}
Halogenated tryptanthrin and aminotryptanthrin were synthesized from indigo or isatin precursors. Dibromo- and tetrabromotryptanthrin were obtained from indigo dyes following green chemistry procedures, through microwave-assisted synthesis in mild oxidation conditions. Spectral and photophysical properties of the compounds, including quantitative determination of all the different deactivation pathways of $S_{1}$ and $T_{1}$, were obtained in different solvents and temperatures. The triplet state $\left(\mathrm{T}_{1}\right)$ has a dominant role on the photophysical properties of these compounds, which is further enhanced by the halogens at the fused-phenyl rings. Substitution with an amino group, 2-aminotryptanthrin (TRYP- $\mathrm{NH}_{2}$ ), leads a dominance of the radiative decay channel. Moreover, with the sole exception of TRYP- $\mathrm{NH}_{2}, \mathrm{~S}_{1} \sim \sim>\mathrm{T}_{1}$ intersystem crossing constitutes the dominant route, with internal conversion playing a minor role in the deactivation of $S_{1}$ in all the studied derivatives. In agreement with tryptanthrin, emission of the triplet state of tryptanthrin derivatives (with exception of TRYP- $\mathrm{NH}_{2}$ ), was observed together with an enhancement of the singlet oxygen sensitization quantum yield: from $70 \%$ in tryptanthrin to $92 \%$ in the iodine derivative. This strongly contrasts with indigo and its derivatives, where singlet oxygen sensitization is found inefficient.
\end{abstract}

\section{Graphic abstract}
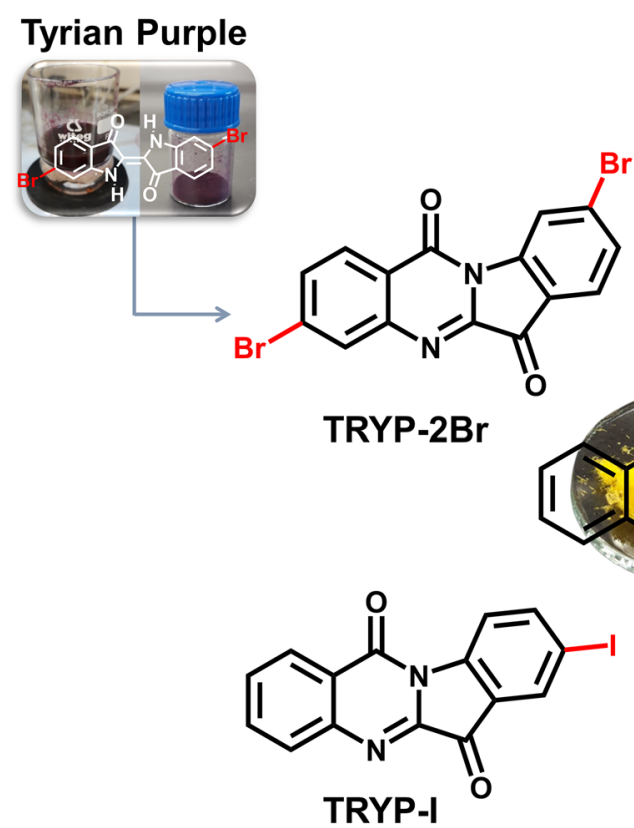

TRYP-I<smiles>O=C1c2cc(Br)cc(Br)c2-n2c1nc1c(Br)cc(Br)cc1c2=O</smiles>

TRYP-4Br

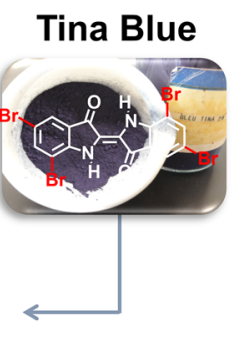

Keywords Tryptanthrin $\cdot$ Tryptanthrin derivatives $\cdot$ Fluorescence $\cdot$ Singlet oxygen sensitization

J. Sérgio Seixas de Melo

sseixas@ci.uc.pt

1 Department of Chemistry, CQC, University of Coimbra, Rua

Larga, 3004-535 Coimbra, Portugal 


\section{Introduction}

Tryptanthrin (indolo[2,1- $b$ ]quinazoline-6,12-dione), abbreviated as TRYP, is a natural compound found in diversified natural sources [1-6] and with several applications. Besides the extraction from natural sources, tryptanthrin can also be synthetically obtained from indigo or isatin increasing the structural diversity of tryptanthrin derivatives [7-11]. To increase the bioactivity of TRYP, several structural modifications have been accomplished. In the past recent years different TRYP derivatives [12-18] as well as its nanoformulations [19] have been synthetized and evaluated for potential biological and pharmacological activity, e.g. antipathogenic, antifungal, antiparasitic, antitubercular, antimalarial, anticancer, antioxidant, and anti-inflammatory [13, 20-29] and, very interesting, as stable active materials for all-organic redox flow batteries [30]. Most of these studies revealed that modification of TRYP core is important to develop novel and widespread potential applications in various fields. Moreover, encapsulation of TRYP in various nanoparticles [31] improves its delivery and its sustained release. These unique properties have led to obtain tryptanthrin derivatives that absorb and emit even at longer wavelength (wavelengths that are desirable for applications in biological systems) as well as fluorescent chemosensors for metal ions [32-38].

Recently the role of $N, N$ '-dimethylformamide (DMF) to act as solvent and oxygen source in the formation of TRYP from indigo was investigated [39], this showed a new approach for the synthesis of TRYP from indigo via

Chart 1 Structures and acronyms of tryptanthrin (TRYP) and the studied tryptanthrin derivatives oxidation to isatin and subsequent oxidative cyclization by using the trio - sodium hydride $(\mathrm{NaH})$, an iodine source and DMF under microwave irradiation [7, 39]. The developed methodology allows the synthesis of new tryptanthrin derivatives from well-known and available indigo dyes. Tyrian purple (6,6'-dibromoindigo or Royal purple) and Tina blue $\left(5,5^{\prime}, 7,7^{\prime}\right.$-tetrabromoindigo, also known as Ciba Blue or Vat Blue 5), were successfully transformed into the corresponding di- and tetra-bromotryptanthrin derivatives. Monosubstituted tryptanthrin derivatives were obtained from the corresponding isatin or isatoic anhydride precursor through condensation, Chart 1 . The comprehensive study of the electronic spectral and photophysical behaviour in solution of this set of tryptanthrin derivatives, including its singlet oxygen sensitization quantum yield clarify the interaction of this class of compounds with light, reveals its differences with indigo parents and open the way to their application as oxygen sensitizers.

\section{Experimental section}

\subsection{Materials}

All the reagents for the synthesis, 1,2-diiodoethane, 4-bromo-2-nitrobenzaldehyde, 5-aminoisatoic anhydride, sodium hydride (60\% dispersion in mineral oil, stored in a dry box) were obtained from Sigma-Aldrich, 5-iodoisatin and Ciba Blue 2B (Tina Blue) were purchased from TCI Chemicals and isatoic anhydride and isatin from Merck. All<smiles>O=C1c2ccccc2-n2c1nc1ccccc1c2=O</smiles>

Tryptanthrin (TRYP)<smiles>O=C1c2ccc(Br)cc2-n2c1nc1cc(Br)ccc1c2=O</smiles>

3,9-Dibromotryptanthrin (TRYP-2Br)<smiles>O=C1c2cc(I)ccc2-n2c1nc1ccccc1c2=O</smiles>

8-lodotryptanthrin (TRYP-I)<smiles>O=C1c2cc(Br)cc(Br)c2-n2c1nc1c(Br)cc(Br)cc1c2=O</smiles>

2,4,8,10-Tetrabromotryptanthrin (TRYP-4Br)

2-Aminotryptanthrin (TRYP-NH ${ }_{2}$ ) 
reagents used for the synthesis of the compounds were used without further purification. For the synthetic procedures, the solvents were of commercial pro analysis (P.A.) grade. For the spectral and photophysical determinations, the solvents used were of spectroscopic or equivalent grade.

\subsection{Equipment and methods}

Microwave (MW)-assisted reactions were performed in a CEM Discover S-Class single-mode microwave reactor, featuring continuous temperature, pressure and microwave power monitoring.

Analytical thin-layer chromatography (TLC) was performed on Macherey-Nagel ALUGRAM Xtra silica gel plates with $\mathrm{UV}_{254}$ indicator. Visualization was accomplished by using an ultraviolet lamp. Silica gel column was carried out with silica gel (230-400 mesh).

Nuclear magnetic resonance (NMR) spectra were recorded at room temperature in deuterated chloroform $\left(\mathrm{CDCl}_{3}\right)$ solutions on a Bruker Avance III spectrometer and a Bruker DRX-400 spectrometer, operating at $400.13 \mathrm{MHz}$ for ${ }^{1} \mathrm{H}$ and $100.61 \mathrm{MHz}$ for ${ }^{13} \mathrm{C}$, and are given in Figures SI1-8 in SI. Chemical shifts ( $\delta$ ) for ${ }^{1} \mathrm{H}$ and ${ }^{13} \mathrm{C}$ are expressed in ppm, relatively to an internal standard of TMS (tetramethylsilane). Coupling constants $(J)$ are indicated in $\mathrm{Hz}$.

Gas chromatography-mass spectroscopy (GC-MS) analyses were performed on a Hewlett-Packard 5973 MSD spectrometer, using electron ionization (EI) $(70 \mathrm{eV})$, coupled with a Hewlett-Packard Agilent 6890 chromatography system, equipped with a HP-5 MS column $(30 \mathrm{~m} \times 0.25 \mathrm{~mm} \times 0.25 \mu \mathrm{m})$ and high-purity helium as carrier gas. The initial temperature of $70^{\circ} \mathrm{C}$ was increased to $250{ }^{\circ} \mathrm{C}$ at a $15^{\circ} \mathrm{C} \mathrm{min}^{-1}$ rate, and held for $10 \mathrm{~min}$. Then the temperature was increased to $290{ }^{\circ} \mathrm{C}$ at a $5{ }^{\circ} \mathrm{C} \mathrm{min}{ }^{-1}$ rate and held for $2 \mathrm{~min}$, giving a total run time of $32 \mathrm{~min}$. The flow of the carrier gas was maintained at $1.33 \mathrm{~mL} \mathrm{~min}^{-1}$. The injector port was set at $250^{\circ} \mathrm{C}$.

High resolution mass spectrometry (HRMS) was performed either on a Bruker microTOF-Focus mass spectrometer equipped with an electrospray ionization time-of-flight (ESI-TOF) source or a Waters-Micromass GC-TOF mass spectrometer equipped with an electron ionization (EI) source. Experimental (red line) and calculated (green line) high resolution mass spectra are given in Figure SI9-12 in SI.

Absorption and fluorescence spectra were recorded on a Shimadzu UV-2450 and Horiba-Jobin-Ivon SPEX Fluorolog 3-22 spectrometers, respectively. Fluorescence spectra were corrected for the wavelength response of the system. For the steady state and time resolved emission experiments, the absorption at the excitation wavelength was kept below 0.1 values to avoid inner-filter, reabsorption or aggregation effects.
The singlet extinction coefficients $\left(\varepsilon_{\mathrm{SS}}\right)$ were obtained from the slope of the plot of the absorption with (at least) five solutions in the range concentration $5 \times 10^{-5}-6 \times 10^{-6} \mathrm{~mol}$ $\mathrm{L}^{-1}$ versus the concentration (correlation values $\geq 0.999$ ) (see Figure SI13 in SI).

The fluorescence quantum yields $\left(\phi_{\mathrm{F}}\right)$ at room temperature $(293 \mathrm{~K})$ were measured by the comparative method using the absolute $\phi_{\mathrm{F}}$ values obtained for TRYP in each solvent [7] as standard using the equation bellow (Eq. 1):

$\phi_{\mathrm{F}}^{\mathrm{cp}}=\frac{\int \mathrm{I}^{\mathrm{cp}}(\lambda) \mathrm{d} \lambda}{\int \mathrm{I}^{\mathrm{ref}}(\lambda) \mathrm{d} \lambda} \cdot \frac{\mathrm{n}_{\mathrm{cp}}^{2}}{\mathrm{n}_{\mathrm{ref}}^{2}} \cdot \phi_{\mathrm{F}}^{\mathrm{ref}}$

where $\int I^{c p}(\lambda) d \lambda$ is the integrated area under the emission spectra of the compound $(c p)$ in solution and $\int I^{\text {ref }}(\lambda) d \lambda$ of the reference (ref) in solution, $\mathrm{n}_{\mathrm{cp}}^{2}$ and $\mathrm{n}_{\mathrm{ref}}^{2}$ are the refractive index of the solvents in which the compound and reference were dissolved, respectively and $\phi_{\mathrm{F}}^{\mathrm{ref}}$ is the fluorescence quantum yield of the standard. The fluorescence quantum yields were obtained with optically matched solutions, at the excitation wavelength, of tryptanthrin derivatives and TRYP.

Phosphorescence measurements were recorded with a Horiba-Jobin-Ivon SPEX Fluorolog 3-22 spectrometer using a $150 \mathrm{~W}$ pulsed Xenon lamp. The phosphorescence spectra were corrected for the wavelength response of the system. Phosphorescence experiments were performed with a quartz NMR-like (EPR) tube. Due to the smaller optical pathway, $l$, an absorbance of $\sim 0.4$ (with a $1 \mathrm{~cm}$ optical length cuvette) was used in contrast to the $\sim 0.1$ used in fluorescence experiments. This tube was put inside a dewar (fixed to the equipment with an appropriate holder) filled up with liquid nitrogen.

The phosphorescence quantum yields were determined using biacetyl $\left(\phi_{\mathrm{Ph}}=0.23\right)$ [40] in a mixed solvent containing diethyl ether, isopentane and ethanol in a 5:5:2(v/v/v) ration as standard [41].

Singlet oxygen formation quantum yields $\left(\phi_{\Delta}\right)$ were obtained by direct measurements of the phosphorescence emission spectrum of singlet oxygen, ${ }^{1} \mathrm{O}_{2}$, centered at $1275 \mathrm{~nm}$ with a Horiba-Jobin-Ivon SPEX Fluorolog 3-22 spectrometer equipped with a near-infrared (NIR) detector Hamamatsu R5509-42 photomultiplier cooled to $193 \mathrm{~K}$ in a liquid nitrogen chamber. To avoid the overlap of the fluorescence emission second harmonic signal with the sensitized singlet oxygen phosphorescence emission at $1275 \mathrm{~nm}$ a Newport long-pass dielectric filter with $1000 \mathrm{~nm}$ cut-on (reference 10LWF-1000-B) was used. The sensitized phosphorescence emission spectra of ${ }^{1} \mathrm{O}_{2}$ from optically matched solutions of the samples and that of the reference compound were obtained in identical experimental conditions $(\Delta \mathrm{OD}=0.20-0.30)$. The singlet oxygen formation quantum yield was then determined by comparing the integrated area under the emission spectra of the sample solutions 
$\left(\int I^{c p}(\lambda) d \lambda\right)$ and that of the reference solution $\left(\int I^{\text {ref }}(\lambda) d \lambda\right)$ and applying the equation (Eq. 2) [42],

$\phi_{\Delta}^{c p}=\frac{\int I^{c p}(\lambda) d \lambda}{I^{r e f}(\lambda) \lambda d \lambda} \cdot \phi_{\Delta}^{r e f}$

with $\phi_{\Delta}^{\text {ref }}$ the singlet oxygen formation quantum yield of the reference compound. $1 \mathrm{H}$-phenalen-1-one in acetonitrile $\left(\phi_{\Delta}=0.98\right)$ as used as standard [43]. Singlet oxygen formation quantum yields were obtained with optically matched solutions, at the excitation wavelength, of tryptanthrin derivatives and $1 \mathrm{H}$-phenalen-1-one.

Fluorescence decays were measured using a home-built picosecond time-correlated single photon counting (psTCSPC) apparatus described elsewhere [44]. The excitation source consists of a tunable picoseconds SpectraPhysics mode-lock Tsunami laser (Ti:Sapphire) model 3950 ( $80 \mathrm{MHz}$ repetition rate, tuning range $700-1000 \mathrm{~nm}$ ), pumped by a $532 \mathrm{~nm}$ continuous wave Spectra-Physics Millennia Pro-10 s laser.

The fluorescence decays and the instrumental response function (IRF) were collected using a time scale corresponding to 1024 channels in a 4.44 or $24.4 \mathrm{ps} /$ channel scale (chosen according to the time scale of the fluorescence decay). The excitation wavelengths used in this work $\left(\lambda_{e x c}=422 \mathrm{~nm}\right)$ were obtained with a Spectra-Physics harmonic generator, model GWU-23PS with time resolution $\sim 2$ ps after deconvolution of the signal (the pulse instrument response is typically of $\sim 20$ ps). When a PicoQuant Picosecond Laser Diode Head, picoLED, model LDH-P-C-450B with $\lambda_{\text {exc }}=451 \mathrm{~nm}$ was used as excitation source, the pulse instrumental response is larger and the time resolution is also lower ( $c a$. $20 \mathrm{ps}$ ). The fluorescence decay curves were analysed by deconvolution using the IRF signal collected with a scattering solution (aqueous Ludox solution). Deconvolution of the decays was performed using the modulation function method, as implemented by George Striker in the SAND program and elsewhere described [45]. Nanosecond transient absorption (ns-TA) spectra were measured with an Applied Photophysics laser flash photolysis equipment pumped by the third harmonic $(355 \mathrm{~nm})$ of a Nd:YAG laser (Spectra Physics). The detection was obtained with an Hamamatsu R928 photomultiplier and a pulsed $150 \mathrm{~W}$ Xe lamp, which were used to analyze the transient absorption. The transient spectra were collected by monitoring the optical density change at intervals of 5-10 nm, averaging at least 10 decays at each wavelength.

\subsection{Synthesis of halogenated tryptanthrin derivatives}

\subsubsection{Synthesis of Tyrian purple (6,6'-dibromoindigo)}

Tyrian purple was synthesized via the Baeyer-Drewsen reaction following a similar procedure for the synthesis of indigo [46, 47]. Using 4-bromo-2-nitrobenzaldehyde as starting material Tyrian was obtained in moderate yields, see Scheme SI1. 4-Bromo-2-nitrobenzaldehyde $(200 \mathrm{mg})$ was dissolved in acetone $(10 \mathrm{~mL})$ and $10 \mathrm{~mL}$ of water was added in small amounts keeping an inert atmosphere $\left(\mathrm{N}_{2}\right)$ and cooling the reaction in an ice bath. 2.0 $\mathrm{M}$ aqueous sodium hydroxide solution was added dropwise keeping the $\mathrm{pH}$ at 10 , until the complete formation of a dark precipitate. The suspension was stirred overnight. The purple precipitate was filtered off, washed several times with acetone and water $(3 \times 20 \mathrm{~mL})$ and dried over vacuum, yielding $105 \mathrm{mg}$ (29\% yield) of 6,6'-dibromoindigo (Tyrian purple). Due to the insolubility of Tyrian purple in various deuterated solvents the ${ }^{1} \mathrm{H}$ and ${ }^{13} \mathrm{C}$ NMR spectra were not collected. EI-TOF-MS: $\mathrm{m} / \mathrm{z}$ $[\mathrm{M}+1]^{+}=419.8923$ calculated for $\mathrm{C}_{16} \mathrm{H}_{9} \mathrm{Br}_{2} \mathrm{~N}_{2} \mathrm{O}_{2}$; found: 419.8932 .

\subsubsection{Synthesis of 3,9-dibromoindolo[2,1-b] quinazoline-6,12-dione, 3,9-dibromotryptanthrin (TRYP-2Br)}

In a thick-glass microwave reactor, with a magnetic stirring bar, Tyrian purple (80 mg, 1 equiv) and sodium hydride ( $\mathrm{NaH}$ ) (2 equiv) were dissolved in $1 \mathrm{~mL}$ of dry $N, N$ '-dimethylformamide (DMF). Then, 1,2-diiodoethane (2 equiv) and DMF were added to a total volume of $2 \mathrm{~mL}$. The resulting mixture was heated under microwave irradiation at $50{ }^{\circ} \mathrm{C}$ for $15 \mathrm{~min}$. The crude was extracted with dichloromethane and purified by column chromatography $\left(\mathrm{SiO}_{2}\right)$ using ethyl acetate/ hexane $(1: 3 ; \mathrm{v} / \mathrm{v})$ as eluent to yield TRYP-2Br as a yellow solid (29 mg, 37\% yield). ${ }^{\mathbf{1}} \mathbf{H}$ NMR $\left(\mathbf{C D C l}_{\mathbf{3}}, \mathbf{4 0 0} \mathbf{~ M H z}\right)$, $8.85(\mathrm{~d}, J=1.5 \mathrm{~Hz}, 1 \mathrm{H}), 8.29(\mathrm{~d}, J=8.5 \mathrm{~Hz}, 1 \mathrm{H}), 8.19 \mathrm{~d}$, $J=1.8 \mathrm{~Hz}, 1 \mathrm{H}), 7.81-7.76(\mathrm{~m}, 2 \mathrm{H}), 7.61(\mathrm{dd}, J=1.6 \mathrm{~Hz}$, $J=8.1 \mathrm{~Hz}, 1 \mathrm{H}) \mathrm{ppm} .{ }^{\mathbf{1 3}} \mathbf{C} \mathbf{~ N M R}\left(\mathbf{C D C l}_{\mathbf{3}}, \mathbf{1 0 1} \mathbf{M H z}\right), \delta 180.0$, $156.4,146.5,145.5,143.9,132.7,132.7,132.4,129.9$, $129.2,127.9,125.3,121.3,120.4,119.5$ ppm. GC-MS: $\mathrm{m} / \mathrm{z}$ $\left[\mathrm{M}^{+}\right]=405.9$. ESI-TOF-MS: $\mathrm{m} / \mathrm{z}[\mathrm{M}+1]^{+}=404.8869 \mathrm{cal}-$ culated for $\mathrm{C}_{15} \mathrm{H}_{7} \mathrm{Br}_{2} \mathrm{~N}_{2} \mathrm{O}_{2}$; found: 404.4886 .

\subsubsection{Synthesis of 2,4,8,10-tetrabromoindolo[2,1-b] quinazoline-6,12-dione, 2,4,8,10-tetrabromotryptanthrin (TRYP-4Br)}

In a thick-glass microwave reactor charged with a magnetic stirring bar, 5,5', 7,7'-tetrabromoindigo (Tina Blue) (200 mg, 1 equiv) and $\mathrm{NaH}$ (2 equiv) were dissolved in $1 \mathrm{~mL}$ of dry 
<smiles>O=C1/C(=C2\Nc3cc(Br)ccc3C2=O)Nc2cc(Br)ccc21</smiles>

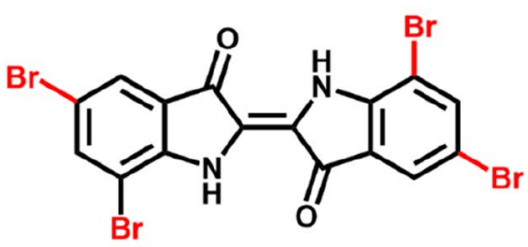

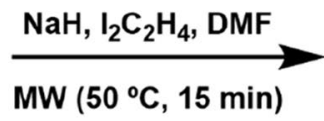<smiles>O=C1c2ccc(Br)cc2-n2c1nc1cc(Br)ccc1c2=O</smiles>

TRYP-2Br

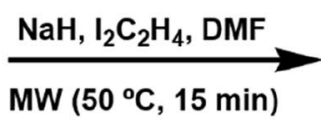

Scheme 1 Schematic pathways for the synthesis of 3,9-dibromotryptanthrin (TRYP-2Br) from Tyrian purple and 2,4,8,10-tetrabromotryptanthrin (TRYP-4Br) from Tina blue

DMF. 1,2-diiodoethane (2 equiv) and DMF were added to a total volume of $2 \mathrm{~mL}$. The resulting mixture was heated under microwave irradiation at $50{ }^{\circ} \mathrm{C}$ for $15 \mathrm{~min}$. After cooling down to room temperature, the reaction mixture was extracted with dichloromethane and water and the organic layer was dried over anhydrous sodium sulfate overnight. The mixture was then filtered and the solvent concentrated under reduce pressure. The crude was purified by column chromatography $\left(\mathrm{SiO}_{2}\right)$ using ethyl acetate/ hexane (1:3; $\mathrm{v} / \mathrm{v}$ ) as eluent to yield TRYP-4Br as a light green solid

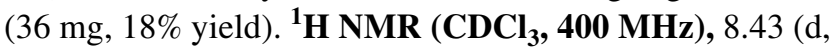
$J=2.1 \mathrm{~Hz}, 1 \mathrm{H}), 8.22$ (d, $J=2.2 \mathrm{~Hz}, 1 \mathrm{H}), 8.15$ (d, $J=1.9 \mathrm{~Hz}$, $1 \mathrm{H}), 8.03(\mathrm{~d}, J=1.9 \mathrm{~Hz}, 1 \mathrm{H}) \mathrm{ppm} .{ }^{13} \mathrm{C}$ NMR (CDCl3, $101 \mathrm{MHz}), \delta 179.4,154.7,145.7,144.6,144.5,143.0$, $141.4,130.0,127.5,127.3,126.7,126.5,124.8,122.0$, 112.04 ppm. ESI-TOF-MS: $\mathrm{m} / \mathrm{z}[\mathrm{M}+1]^{+}=560.7079 \mathrm{cal}-$ culated for $\mathrm{C}_{15} \mathrm{H}_{5} \mathrm{Br}_{4} \mathrm{~N}_{2} \mathrm{O}_{2}$; found: 560.7074 .

\subsubsection{Synthesis of 8-iodoindolo[2,1-b] quinazoline-6,12-dione, 8-iodotryptanthrin (TRYP-I) and 2-aminoindolo[2,1-b]quinazoline-6,12-dione, 2-aminotryptanthrin (TRYP- $\mathrm{NH}_{2}$ )}

Mono-substituted tryptanthrin derivatives were synthesized following a previously reported procedure [15]. Briefly, a solution of isatin (500 mg, 1 equiv) in $10 \mathrm{~mL}$ of DMF was added over a $15 \mathrm{~min}$ period to $\mathrm{NaH}$ solution ( $43 \mathrm{mg}, 1$ equiv) with stirring. To the resulting purple liquid, isatoic anhydride (323 mg, 1.1 equiv) in $10 \mathrm{~mL}$ of DMF was added keeping the reaction on ice over a 30 min period. The reaction mixture was stirred $48 \mathrm{~h}$ at room temperature and then quenched with $10 \mathrm{~mL}$ of methanol. The resulting mixture was diluted with $50 \mathrm{~mL}$ of chloroform and washed once with water. The aqueous layer was extracted three times with chloroform and the combined organic layers were concentrated under reduce pressure. Crystallization from acetone afforded the pure tryptanthrin derivatives.

TRYP-I: yellow solid (626 mg, 93\% yield). ${ }^{\mathbf{1}} \mathbf{H}$ NMR $\left.\mathbf{~} \mathbf{C D C l}_{3}, 400 \mathrm{MHz}\right), 8.45-8.46(\mathrm{~m}, 2 \mathrm{H}), 8.21$ (dd, $J=1.7 \mathrm{~Hz}, 1 \mathrm{H}), 8.08(\mathrm{dd}, J=1.8 \mathrm{~Hz}, J=8.5 \mathrm{~Hz}, 1 \mathrm{H}), 8.02$ $(\mathrm{d}, J=7.9 \mathrm{~Hz}, 1 \mathrm{H}), 7.86(\mathrm{dt}, J=1.6 \mathrm{~Hz}, J=7.2 \mathrm{~Hz}, 1 \mathrm{H}), 7.68$ $(\mathrm{dt}, J=1.2 \mathrm{~Hz}, J=7.2 \mathrm{~Hz}, 1 \mathrm{H}) \mathrm{ppm} .{ }^{13} \mathbf{C}$ NMR (DMSO-d , 101 MHz), 180.8, 157.9, 149.2, 146.1, 145.6, 145.2, 135.8, 132.6, 130.3, 130.1, 127.2, 123.1, 122.8, 119.5, 117.7 ppm. ESI-TOF-MS: $\mathrm{m} / \mathrm{z}[\mathrm{M}+1]^{+}=374.9625$ calculated for $\mathrm{C}_{15} \mathrm{H}_{8} \mathrm{IN}_{2} \mathrm{O}_{2}$; found: 374.9629 .

TRYP-NH ${ }_{2}$ : dark brown solid (734 mg, $82 \%$ yield). ${ }^{1} \mathbf{H}$ NMR (400 MHz, CDCl ${ }_{3}$ ), $\delta 8.86(\mathrm{~d}, J=8.9 \mathrm{~Hz}, 1 \mathrm{H}), 8.76$ $(\mathrm{d}, J=2.1 \mathrm{~Hz}, 1 \mathrm{H}), 8.69(\mathrm{dd}, J=2.2 \mathrm{~Hz}, J=8.9 \mathrm{~Hz}, 1 \mathrm{H})$, $8.48(\mathrm{~d}, J=7.3 \mathrm{~Hz}, 1 \mathrm{H}), 8.07$ (d, J = 8.0 Hz, 1H), 7.92 (dt, $J=1.2 \mathrm{~Hz}, J=6.8 \mathrm{~Hz}, 1 \mathrm{H}), 7.74(\mathrm{t}, J=7.4 \mathrm{~Hz}, 1 \mathrm{H}) \mathrm{ppm} .{ }^{13} \mathrm{C}$ NMR (CDCI3, 101 MHz), $\delta 181.1,157.6,146.4,145.5$, 145.2, 144.5, 135.3, 132.6, 130.0, 130.0, 127.0, 124.2, 123.1, 119.0, 91.4 ppm. ESI-TOF-MS: $\mathrm{m} / \mathrm{z}[\mathrm{M}+1]^{+}=264.0768$ calculated for $\mathrm{C}_{15} \mathrm{H}_{10} \mathrm{~N}_{3} \mathrm{O}_{2}$; found: 264.0770.

\section{Results and discussion}

\subsection{Synthesis of tryptanthrin derivatives}

The two bromo tryptanthrin derivatives, 3,9-dibromotryptanthrin (TRYP-2Br) and 2,4,8,10-tetrabromotryptanthrin (TRYP-4Br), were successful synthesized from Tyrian purple and Tina blue, respectively. The synthetic methodology previously developed by our research group [7, 39] for the synthesis of TRYP from indigo, allows the synthesis of tryptanthrins with two or four bromine atoms from the respective indigo dyes. Using the oxidant system formed by the trio- $\mathrm{NaH}, 1,2$-diodoethane and DMF and microwave irradiation [39], the limitative characteristic of low 


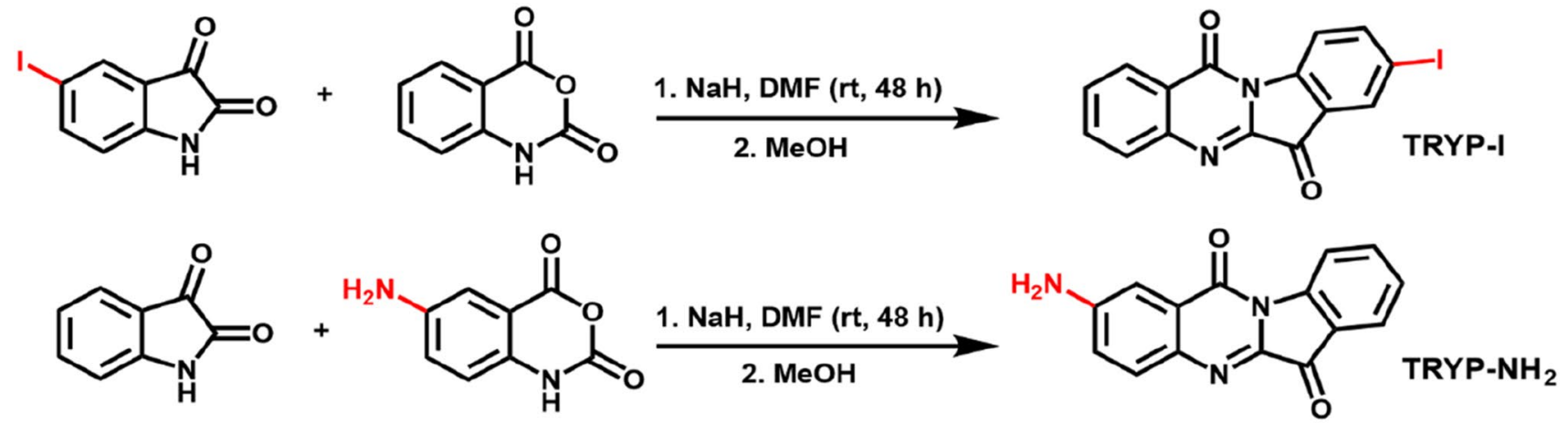

Scheme 2 Synthesis of 8-iodotryptanthrin (TRYP-I) and 2-aminotryptanthrin (TRYP-NH$)$

solubility of these indigo dyes in organic solvents was overcome and tryptanthrin analogues were obtained in moderate oxidative conditions and short reaction times, see Scheme 1. Even considering the relatively moderated reaction yields obtained using this methodology, the significant reduction on the amount of solvent needed to perform the reaction has a positive impact in the E-Factor (environmental factor [48]) decreasing from 187 -calculated for the synthesis of 3,9-dibromotryptanthrin from 5-bromoisatin and 5-bromoisatoic anhydride in $80 \%$ yield following the experimental procedure herein described for the synthesis of monosubstituted tryptanthrin derivatives - to 72 , implying that a reduction of the mass of waste produce to less than a half has occurred (see Table SI1).

The two mono-substituted tryptanthrin derivatives, 8-iodotryptanthrin (TRYP-I) and 2-aminotryptanthrin (TRYP-NH $\mathrm{N}_{2}$ ), were obtained from the condensation of anthranilic acid derivatives, in particular isatoic anhydrides, with isatin in the presence of a base. The use of $\mathrm{NaH}$ instead of triethylamine [25] allows to obtain the desired product after $48 \mathrm{~h}$ at room temperature, in excellent yields after simple recrystallization (Scheme 2).

\subsection{Excited state characterization}

\subsubsection{Absorption and steady state fluorescence spectral data}

The absorption and fluorescence, emission and excitation, spectra of the tryptanthrin derivatives obtained at room temperature $(\mathrm{T}=293 \mathrm{~K})$ in acetonitrile $(\mathrm{MeCN})$ are depicted in Fig. 1. Full spectra, including in other solvents (ethanol $(\mathrm{EtOH})$ and methanol $(\mathrm{MeOH}))$, are given in Figure SI14. Similarly to TRYP, the absorption spectra of the different tryptanthrin derivatives, with exception of TRYP-NH remains relatively unaffected with the polarity and/or hydrogen bonding ability of the solvent [7]. Noteworthy is the different spectral behaviour of TRYP-NH 2 , i.e., absence of the absorption band at shorter wavelengths $(\sim 350 \mathrm{~nm})$, see Fig. 1 and Figure SI14. It is also worth noting the broad emission spectra of the bromine and iodine tryptanthrin spectra, contrasting with the more narrowed nature of the TRYP-NH ${ }_{2}$ spectrum.

Table 1 summarizes the spectral data for the studied tryptanthrin derivatives. Di-substitution with bromine atoms (TRYP-2Br) leads to a small blue shift in the fluorescence emission when compared with TRYP. Further increment on the degree of substitution with two more bromine atoms (TRYP-4Br), with an iodine atom (TRYP-I), or an amino group (TRYP-NH${ }_{2}$ ) leads to red-shifts of the emission (Table 1, Fig. 1).

The fluorescence emission spectra of TRYP and derivatives are found solvent dependent, with particular emphasis in TRYP-NH $\mathrm{N}_{2}$ where the large positive solvatochromism, of the fluorescence spectra, has been associated to an effective intramolecular charge transfer (ICT) character involving the carbonyl group of the five-membered ring and the amino group [49]. Additionally, for the four studied compounds molar absorption coefficients were found with the same order of magnitude, and typical of $\pi-\pi^{*}$ transitions, with $\varepsilon_{\mathrm{SS}}$ $\approx 10^{3} \mathrm{M}^{-1} \mathrm{~cm}^{-1}$. These values are in agreement with those previously reported for tryptanthrin [7] and other tryptanthrin derivatives $[36,50,51]$.

\subsubsection{Photophysics: quantum yields}

Data in Table 2 shows that substitution in the TRYP core influences the excited state deactivation pathways. Introduction of the amino group, TRYP- $\mathrm{NH}_{2}$, leads to a high fluorescence quantum yield $\left(\phi_{\mathrm{F}}\right)$ value and a relatively low (in comparison with the other three compounds studied) singlet oxygen sensitization yield $\left(\phi_{\Delta} \sim 0.1\right)$ and absence of phosphorescence emission.

Photophysical data in Table 2 show that the donor amino group, TRYP-NH $\mathrm{N}_{2}$, strongly facilitates the radiative deactivation route with solvent dependent fluorescence quantum 
Fig. 1 Normalized absorption (black line), excitation (blue line) and fluorescence emission (red line) spectra for TRYP (A), TRYP$2 \mathrm{Br}(\mathbf{B})$, TRYP-4Br (C), TRYP-I (D) and TRYP-NH 2 (E) in MeCN solution at $T=293 \mathrm{~K}$. The emission spectra were obtained with $\lambda_{e x c}=330-450 \mathrm{~nm}$ and the excitation spectra with $\lambda_{e m}=500-590 \mathrm{~nm}$. The dashed vertical line is just meant to be a guideline to the eye in particular to the red-shift of the emission band

yields (ranging from 0.2 to 0.8 ). Introduction of the heavy atoms, iodine and bromine, strongly increases sensitization of singlet oxygen, via efficient spin-orbit coupling, with quantum yields, $\phi_{\Delta} \sim 90 \%$ (Table 2 and Figure SI15) in the order TRYP-I > TRYP-2Br TRYP-4Br > TRYP [7]; this is followed by a decrease in the fluorescence quantum yields with values, for all the compounds, lower in polar protic solvents than in polar aprotic solvents, particularly evident for TRYP and TRYP-NH $\mathrm{N}_{2}$. Moreover, exception made to TRYP-NH ${ }_{2}$, the triplet state formation quantum yields, $\phi_{\mathrm{T}}$ -here assumed to be identical to the singlet oxygen yield, i.e., $\phi_{\mathrm{T}} \sim \phi_{\Delta}-$ constitutes the dominant deactivation for all the tryptanthrin derivatives, with the internal conversion (IC) playing a minor role in the deactivation of the $S_{1}$ state in all the studied derivatives.

Characterization of the triplet state was further complemented with the determination of phosphorescence quantum yields and lifetimes. Figure 2 shows the phosphorescence emission spectra for TRYP-2Br, TRYP-4Br and TRYP-I collected in vitreous ethanol at $T=77 \mathrm{~K}$. In agreement to what was observed for TRYP [7], the studied derivatives display a broad phosphorescence emission band, with two vibronic bands, that partially overlaps the fluorescence emission band (also collected at low temperature, $77 \mathrm{~K}$ ), as illustrated in Figure SI16.

From Fig. 2, Table 2 it is seen that the phosphorescence quantum yields are generally low with values ranging from $\phi_{\mathrm{Ph}}=0.0027$ (TRYP) and $\phi_{\mathrm{Ph}}=0.038$ (TRYP-I). The low phosphorescence quantum yields and high quantum yields for singlet oxygen formation are associated with, the phosphorescence quantum yields obtained at $77 \mathrm{~K}$ (that strongly increases the radiative deactivation from $\mathrm{T}_{1}$ at the expenses of the radiationless deactivation) whereas the singlet oxygen sensitization (and triplet state) quantum yields are obtained at room temperature.

Phosphorescence lifetimes were found in the ms time scale $\left(\tau_{\mathrm{Ph}}<0.01 \mathrm{~s}\right)$, phosphorescence decays in Figure SI17, indicating the nature of the triplet state to be of $n, \pi^{*}$ origin [52]. The very efficient $S_{1} \sim>T_{1}$ process indicates, together with the small singlet-triplet energy gap $\left(\Delta \mathrm{E}_{\mathrm{S}-\mathrm{T}}=0.23 \mathrm{eV}-0.45 \mathrm{eV}\right)$, see Table SI2, that according to El-Sayed rules [53], the interacting singlet $\left(\mathrm{S}_{1}\right)$ and triplet $\left(\mathrm{T}_{\mathrm{n}}\right)$ are of different origin and, as with TRYP [7], $\mathrm{S}_{1}$ is of $\pi, \pi^{*}$ origin.

Transient singlet-triplet difference absorption spectra of tryptanthrin and derivatives obtained by laser flash

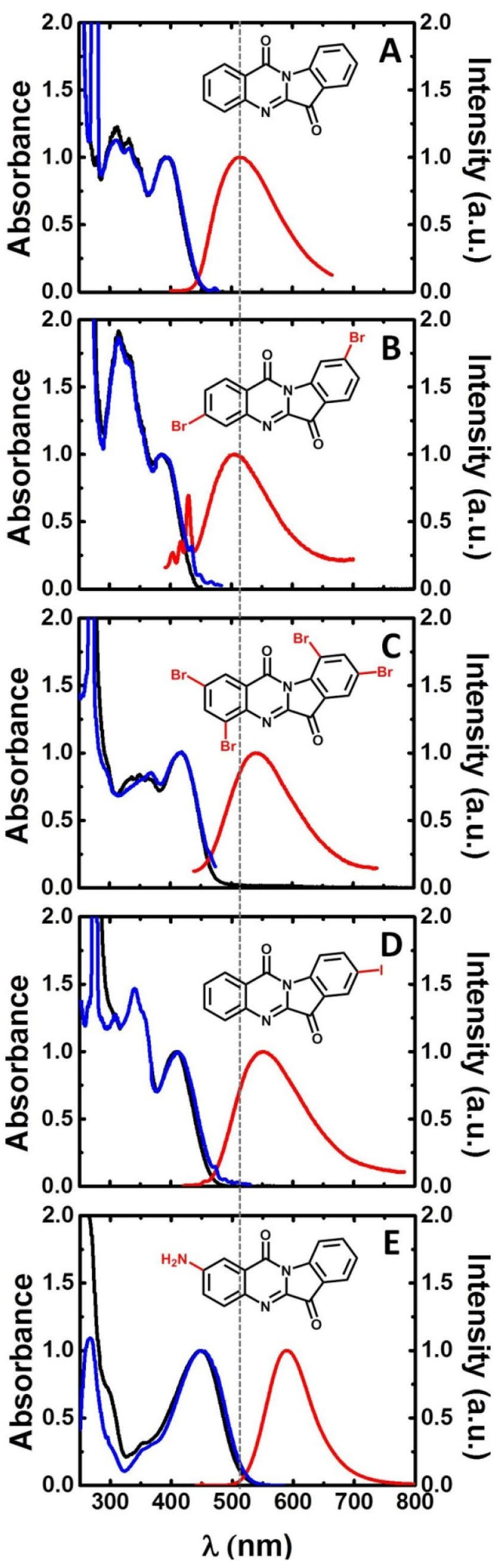


Table 1 Spectral data including absorption $\left(\lambda_{\mathrm{Abs}}\right)$, fluorescence $\left(\lambda_{\text {Fluo }}\right)$ and phosphorescence $\left(\lambda_{\mathrm{Ph}}\right)$ wavelength maxima, Stokes shifts $\left(\Delta_{\mathrm{SS}}\right)$ and molar absorption coefficient $\left(\varepsilon_{\mathrm{SS}}\right)$ for TRYP and derivatives in solvents of different dielectric constant $(\varepsilon)$, at $T=293 \mathrm{~K}$ and $T=77 \mathrm{~K}$

\begin{tabular}{|c|c|c|c|c|c|c|c|}
\hline Compound & Solvent & $\varepsilon^{b}$ & $\begin{array}{l}\lambda_{\mathrm{Abs}} \\
(\mathrm{nm}) \\
(293 \mathrm{~K})\end{array}$ & $\begin{array}{l}\lambda_{\text {Fluo }} \\
(\mathrm{nm}) \\
(293 \mathrm{~K})\end{array}$ & $\begin{array}{l}\lambda_{\mathrm{Ph}} \\
(\mathrm{nm}) \\
(77 \mathrm{~K})\end{array}$ & $\begin{array}{l}\Delta_{\mathrm{SS}} \\
\left(\mathrm{cm}^{-1}\right) \\
(293 \mathrm{~K})\end{array}$ & $\begin{array}{l}\varepsilon_{\mathrm{SS}} \\
\left(\mathrm{M}^{-1} \mathrm{~cm}^{-1}\right) \\
(293 \mathrm{~K})\end{array}$ \\
\hline \multirow[t]{3}{*}{$\mathrm{TRYP}^{a}$} & $\mathrm{MeCN}$ & 35.9 & 394 & 513 & N.D. ${ }^{c}$ & 5888 & 3545 \\
\hline & EtOH & 24.6 & 389 & 539 & 567,615 & 7154 & 4169 \\
\hline & МeOH & 32.7 & 389 & 552 & N.D. ${ }^{c}$ & 7591 & 3736 \\
\hline \multirow[t]{3}{*}{ TRYP-2Br } & $\mathrm{MeCN}$ & 35.9 & 386 & 506 & N.D. ${ }^{c}$ & 6144 & 5197 \\
\hline & EtOH & 24.6 & 383 & 534 & 561,602 & 7383 & 4752 \\
\hline & МeOH & 32.7 & 384 & 543 & N.D. ${ }^{c}$ & 7625 & 4374 \\
\hline \multirow[t]{3}{*}{ TRYP-4Br } & $\mathrm{MeCN}$ & 35.9 & 416 & 540 & N.D. ${ }^{c}$ & 5520 & 8736 \\
\hline & EtOH & 24.6 & 410 & 556 & 575,629 & 6405 & 5660 \\
\hline & МeOH & 32.7 & 410 & 567 & N.D. ${ }^{c}$ & 6754 & 6973 \\
\hline \multirow[t]{3}{*}{ TRYP-I } & $\mathrm{MeCN}$ & 35.9 & 410 & 551 & N.D. ${ }^{c}$ & 6241 & 6812 \\
\hline & EtOH & 24.6 & 407 & 573 & 575,613 & 7118 & 3424 \\
\hline & МeOH & 32.7 & 405 & 591 & N.D. ${ }^{c}$ & 7771 & 4786 \\
\hline \multirow[t]{3}{*}{ TRYP-NH ${ }_{2}$} & $\mathrm{MeCN}$ & 35.9 & 450 & 590 & - & 5273 & 6935 \\
\hline & EtOH & 24.6 & 475 & 631 & - & 5205 & 6737 \\
\hline & МeOH & 32.7 & 463 & 639 & - & 5949 & 5732 \\
\hline
\end{tabular}

${ }^{a}$ For TRYP data is from ref [7]

${ }^{b}$ Values are from ref [41]

${ }^{\mathrm{c}} N . D .=$ Not determined
Table 2 Photophysical data including fluorescence $\left(\phi_{\mathrm{F}}\right)$, phosphorescence $\left(\phi_{\mathrm{Ph}}\right)$, intersystem crossing triplet through ${ }^{1} \mathrm{O}_{2}$ sensitization $\left(\phi_{\Delta} \approx \phi_{\mathrm{T}}\right)$ and internal conversion $\left(\phi_{\mathrm{IC}}\right)$ quantum yields, fluorescence $\left(\tau_{\mathrm{F}}\right)$ and phosphorescence lifetimes $\left(\tau_{\mathrm{Ph}}\right)$ and rate constants (fluores- cence $\left(k_{\mathrm{F}}\right)$, nonradiative $\left(k_{\mathrm{NR}}\right)$, internal conversion $\left(k_{\mathrm{IC}}\right)$ and intersystem crossing $\left.\left(k_{\mathrm{ISC}}\right)\right)$ for tryptanthrin derivatives in solvents of different dielectric constant $(\varepsilon)$, at $T=293 \mathrm{~K}$ and $T=77 \mathrm{~K}$. Data for TRYP is also presented for comparison

\begin{tabular}{|c|c|c|c|c|c|c|c|c|c|c|c|c|}
\hline Compound & Solvent & $\varepsilon^{b}$ & $\begin{array}{l}\phi_{\mathrm{F}} \\
(293 \mathrm{~K})\end{array}$ & $\begin{array}{l}\tau_{\mathrm{F}} \\
(\mathrm{ps})^{c} \\
(293 \mathrm{~K})\end{array}$ & $\begin{array}{l}\phi_{\mathrm{Ph}} \\
(77 \mathrm{~K})\end{array}$ & $\begin{array}{l}\tau_{\mathrm{Ph}} \\
(\mathrm{ms}) \\
(77 \mathrm{~K})\end{array}$ & $\begin{array}{l}\phi_{\Delta} \approx \phi_{\mathrm{T}}{ }^{d} \\
(293 \mathrm{~K})\end{array}$ & $\begin{array}{l}\phi_{\mathrm{IC}} \\
(293 \mathrm{~K})\end{array}$ & $\begin{array}{l}k_{\mathrm{F}} \\
\left(\mathrm{ns}^{-1}\right)^{e} \\
(293 \mathrm{~K})\end{array}$ & $\begin{array}{l}k_{\mathrm{NR}} \\
\left(\mathrm{ns}^{-1}\right)^{e} \\
(293 \mathrm{~K})\end{array}$ & $\begin{array}{l}k_{\mathrm{IC}} \\
\left(\mathrm{ns}^{-1}\right)^{e} \\
(293 \mathrm{~K})\end{array}$ & $\begin{array}{l}k_{\mathrm{ISC}} \\
\left(\mathrm{ns}^{-1}\right)^{e} \\
(293 \mathrm{~K})\end{array}$ \\
\hline \multirow[t]{3}{*}{ TRYP $^{a}$} & MeCN & 35.9 & 0.0084 & 499 & \multirow{3}{*}{0.0027} & & \multirow[t]{3}{*}{0.77} & \multirow[t]{3}{*}{0.22} & 0.017 & 1.987 & \multirow[t]{3}{*}{0.440} & \multirow[t]{3}{*}{1.547} \\
\hline & EtOH & 24.6 & 0.0028 & 255 & & \multirow[t]{2}{*}{10.34} & & & 0.011 & 3.911 & & \\
\hline & МeOH & 32.7 & 0.0019 & 146 & & & & & 0.013 & 6.836 & & \\
\hline \multirow[t]{3}{*}{ TRYP-2BR } & MeCN & 35.9 & 0.0027 & 109 & \multirow{3}{*}{0.0215} & \multirow{3}{*}{4.52} & \multirow[t]{3}{*}{0.91} & \multirow[t]{3}{*}{0.090} & 0.025 & 9.150 & \multirow[t]{3}{*}{0.828} & \multirow[t]{3}{*}{8.322} \\
\hline & EtOH & 24.6 & 0.0017 & 193 & & & & & 0.009 & 5.173 & & \\
\hline & МeOH & 32.7 & 0.0018 & 174 & & & & & 0.010 & 5.737 & & \\
\hline \multirow[t]{3}{*}{ TRYP-4BR } & $\mathrm{MeCN}$ & 35.9 & 0.0015 & 119 & \multirow{3}{*}{0.0063} & \multirow{3}{*}{4.34} & \multirow[t]{3}{*}{0.84} & \multirow[t]{3}{*}{0.16} & 0.013 & 8.391 & \multirow[t]{3}{*}{1.241} & \multirow[t]{3}{*}{7.150} \\
\hline & EtOH & 24.6 & 0.0013 & 89 & & & & & 0.015 & 11.221 & & \\
\hline & МeOH & 32.7 & 0.0011 & 68 & & & & & 0.016 & 14.690 & & \\
\hline \multirow[t]{3}{*}{ TRYP-I } & $\mathrm{MeCN}$ & 35.9 & 0.0011 & 82 & & & 0.92 & 0.080 & 0.013 & 12.182 & 0.901 & 11.280 \\
\hline & EtOH & 24.6 & 0.0009 & 40 & 0.0384 & 1.23 & & & 0.023 & 24.978 & & \\
\hline & МеOH & 32.7 & 0.0008 & 41 & & & & & 0.020 & 24.371 & & \\
\hline TRYP-NH $_{2}$ & MeCN & 35.9 & 0.81 & 2987 & & & 0.10 & 0.085 & 0.271 & 0.064 & 0.029 & 0.035 \\
\hline & EtOH & 24.6 & 0.30 & 1144 & - & - & & & 0.258 & 0.616 & & \\
\hline & МeOH & 32.7 & 0.19 & 832 & & & & & 0.232 & 0.970 & & \\
\hline
\end{tabular}

${ }^{a}$ For TRYP data from ref [7]

${ }^{b}$ Values taken from ref [41]

${ }^{c}$ The decay time considered here is the longer component in the fluorescence decays

${ }^{d}$ Assuming efficient singlet oxygen photosensitization, $\mathrm{S}_{\Delta}=\phi_{\Delta} / \phi_{\mathrm{T}} \approx 1$, from the investigated sample

${ }^{e} k_{F}=\frac{\phi_{F}}{\tau_{F}} ; k_{N R}=\frac{1-\phi_{F}}{\tau_{F}} ; k_{I C}=\frac{1-\phi_{F}-\phi_{T}}{\tau_{F}} ; k_{I S C}=\frac{\phi_{T}}{\tau_{F}} ; \phi_{I C}=1-\phi_{F}-\phi_{T}$ 


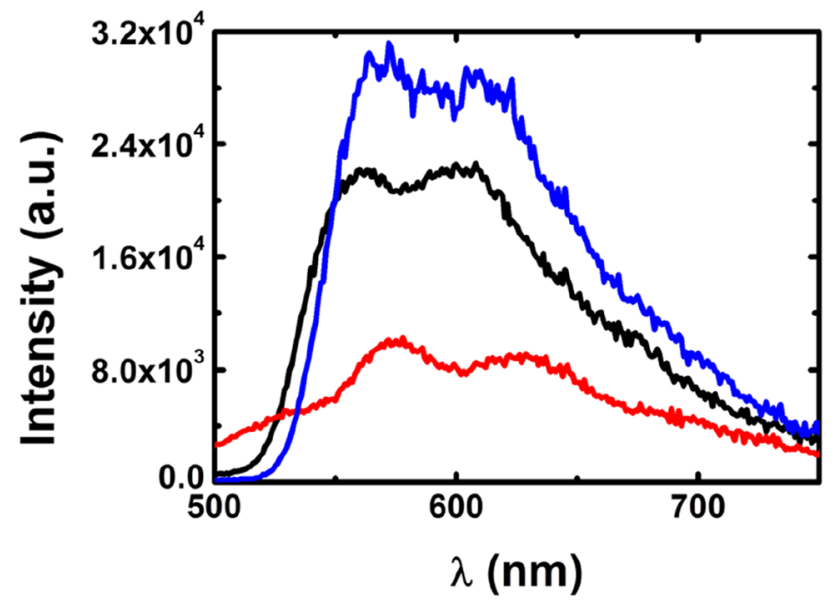

Fig. 2 Phosphorescence emission spectra of TRYP-2Br (black line), TRYP-4Br (red line) and TRYP-I (blue line) in vitreous EtOH at $T=77 \mathrm{~K}$

photolysis with excitation at $355 \mathrm{~nm}$ in degassed $\mathrm{MeCN}$ solution are depicted in Fig. 3.

The transient lifetimes are found quenched by oxygen and thus the observed spectroscopic features are assigned
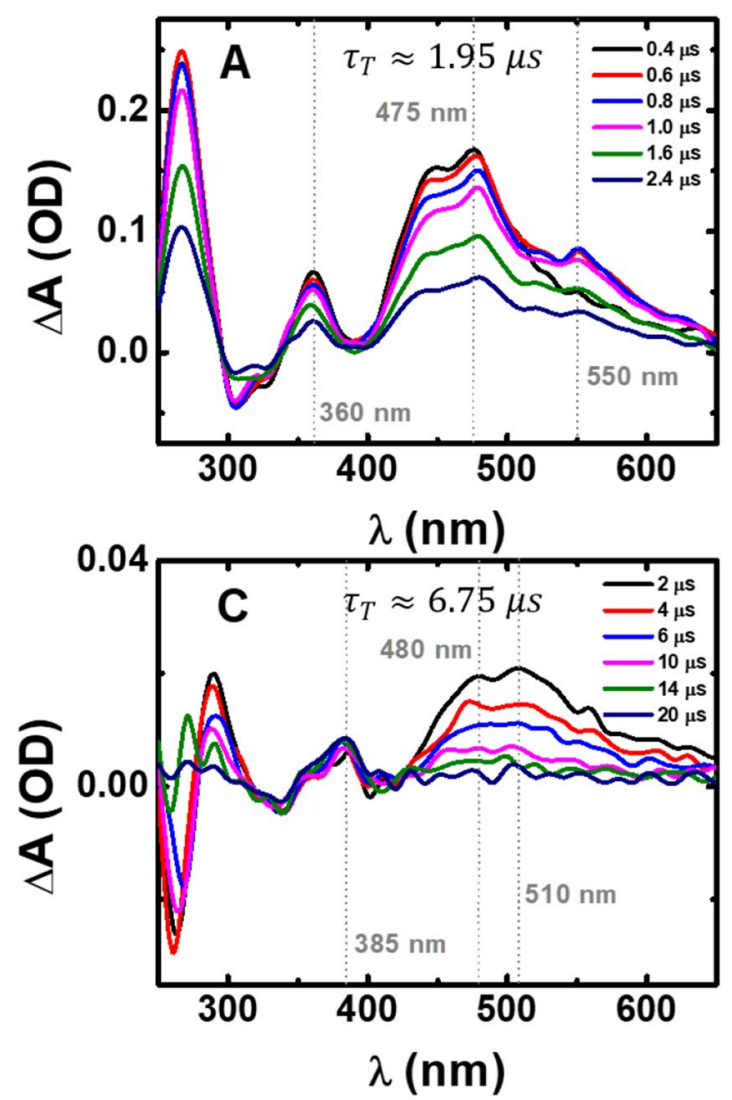

Fig. 3 Room-temperature transient singlet-triplet difference absorption spectra and triplet lifetimes obtained by nanosecond-microsecond transient absorption spectra (ns-TA) for TRYP (A), TRYP-2Br to triplet excited state absorption. In the absence of oxygen all triplet lifetimes are found in the $\mu s$ time range. The triplet lifetime for TRYP-I (Fig. 3D) is similar to the value of TRYP $\left(\tau_{T} \approx 2 \mu s\right)$ (Fig. 3A), while, the compounds TRYP2Br (Fig. 3B) and TRYP-4Br (Fig. 3C) presented higher transient lifetimes $\left(\tau_{T} \approx 7 \mu s\right)$. Similar triplet lifetimes were found all over the transient difference absorption bands.

\subsubsection{Photophysics: time-resolved fluorescence}

Further insights of the decay mechanisms were obtained from time-resolved fluorescence experiments in oxygen and oxygen free solutions for the different tryptanthrin derivatives (Table 3 and Table SI3 in SI). With the exception of TRYP-I, similar results were found for the fluorescence lifetimes in oxygen and free oxygen solutions. For TRYP-I, it was found that for UV light irradiated $\mathrm{N}_{2}$ degassed solutions the colour changes from yellow to orange (Figure SI18). The decomposition of organic compounds containing iodine in solution by UV light has been the subject of some investigations and it has been shown that iodine is released after UV light irradiation [54, 55].
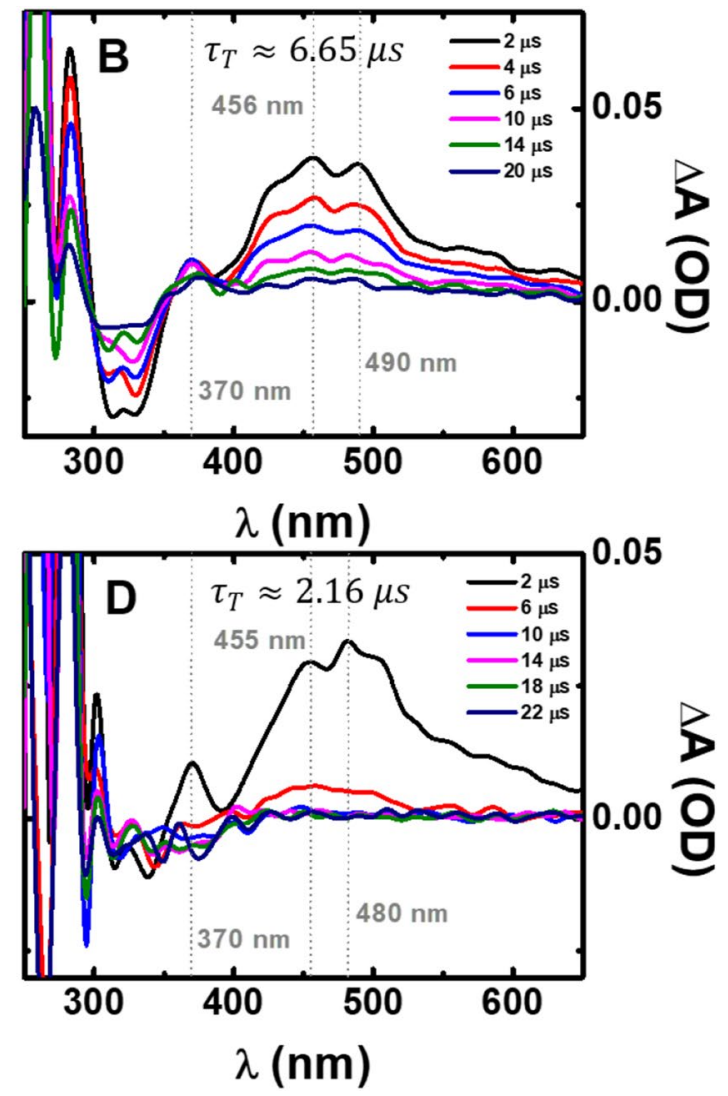

(B), TRYP-4Br (C) and TRYP-I (D) collected with excitation at $355 \mathrm{~nm}$ in degassed MeCN solutions at $T=293 \mathrm{~K}$ 
Table 3 Room temperature time resolved fluorescence data (lifetimes, $\tau_{\mathrm{i}}$, normalized pre-exponential factors, $a_{i i}$, and Chi squared values, $\chi^{2}$ ) obtained with picoseconds time-correlated single photon counting (ps-TCSPC) technique for the different tryptanthrin derivatives in solutions with oxygen, collected with excitation, $\lambda_{e x c}$, ranging from 409 to $451 \mathrm{~nm}$ and at different emission wavelengths (along the emission band)

\begin{tabular}{|c|c|c|c|c|c|c|c|c|}
\hline Compound & $\begin{array}{l}\lambda_{\text {exc }} \\
(\mathrm{nm})\end{array}$ & Solvent & $\begin{array}{l}\lambda_{\mathrm{em}} \\
(\mathrm{nm})\end{array}$ & $\begin{array}{l}\tau_{1} \\
(\mathrm{ps})\end{array}$ & $\begin{array}{l}\tau_{2} \\
(\mathrm{ps})\end{array}$ & $a_{1}$ & $a_{2}$ & $X^{2}$ \\
\hline \multirow[t]{9}{*}{$\mathrm{TRYP}^{a}$} & \multirow[t]{3}{*}{411} & \multirow[t]{3}{*}{ MecN } & 480 & \multirow[t]{3}{*}{65} & \multirow[t]{3}{*}{499} & 0.15 & 0.85 & 1.06 \\
\hline & & & 510 & & & 0.11 & 0.89 & 1.16 \\
\hline & & & 630 & & & 0.05 & 0.95 & 1.12 \\
\hline & \multirow[t]{3}{*}{422} & \multirow[t]{3}{*}{ EtOH } & 490 & \multirow[t]{3}{*}{23} & \multirow[t]{3}{*}{255} & 0.78 & 0.22 & 1.07 \\
\hline & & & 540 & & & 0.42 & 0.59 & 0.92 \\
\hline & & & 620 & & & -0.27 & 1.00 & 0.91 \\
\hline & \multirow[t]{3}{*}{409} & \multirow[t]{3}{*}{ МeOH } & 500 & \multirow[t]{3}{*}{12} & \multirow[t]{3}{*}{146} & 0.73 & 0.27 & 1.23 \\
\hline & & & 550 & & & 0.25 & 0.75 & 1.13 \\
\hline & & & 600 & & & -0.48 & 1.00 & 1.34 \\
\hline \multirow[t]{8}{*}{ TRYP-2Br } & \multirow[t]{8}{*}{422} & \multirow[t]{2}{*}{$\mathrm{MeCN}$} & 460 & \multirow[t]{2}{*}{15} & \multirow[t]{2}{*}{109} & 0.39 & 0.61 & 1.02 \\
\hline & & & 510 & & & 0.28 & 0.72 & 0.96 \\
\hline & & \multirow[t]{3}{*}{ EtOH } & 480 & \multirow[t]{3}{*}{12} & \multirow[t]{3}{*}{193} & 0.89 & 0.10 & 1.21 \\
\hline & & & 530 & & & 0.56 & 0.45 & 1.09 \\
\hline & & & 570 & & & 0.33 & 0.67 & 1.09 \\
\hline & & \multirow[t]{3}{*}{ МeOH } & 480 & \multirow[t]{3}{*}{12} & \multirow[t]{3}{*}{174} & 0.86 & 0.14 & 1.00 \\
\hline & & & 540 & & & 0.36 & 0.64 & 0.93 \\
\hline & & & 570 & & & 0.19 & 0.81 & 1.03 \\
\hline TRYP-4Br & 422 & $\mathrm{MeCN}$ & 480 & 7 & 119 & 0.80 & 0.20 & 1.13 \\
\hline & & & 540 & & & 0.61 & 0.39 & 1.10 \\
\hline & & & 580 & & & 0.52 & 0.48 & 0.99 \\
\hline & & EtOH & 500 & 12 & 89 & 0.91 & 0.09 & 1.14 \\
\hline & & & 550 & & & 0.75 & 0.25 & 1.23 \\
\hline & & & 590 & & & 0.58 & 0.42 & 1.10 \\
\hline & & МеОН & 500 & 10 & 68 & 0.88 & 0.12 & 1.05 \\
\hline & & & 570 & & & 0.42 & 0.58 & 1.14 \\
\hline & & & 610 & & & -0.23 & 1.00 & 1.18 \\
\hline TRYP-I & 422 & MeCN & 490 & 12 & 82 & 0.56 & 0.44 & 1.10 \\
\hline & & & 550 & & & 0.53 & 0.46 & 1.29 \\
\hline & & & 590 & & & 0.48 & 0.51 & 1.14 \\
\hline & & EtOH & 510 & 8 & 40 & 0.94 & 0.06 & 1.23 \\
\hline & & & 570 & & & 0.68 & 0.32 & 0.94 \\
\hline & & МeOH & 560 & 13 & 41 & 0.66 & 0.34 & 0.96 \\
\hline & & & 600 & & & 0.36 & 0.64 & 1.07 \\
\hline TRYP-NH ${ }_{2}$ & 451 & MeCN & 520 & & 2987 & & 1.00 & 1.25 \\
\hline & & & 590 & & & & 1.00 & 1.10 \\
\hline & & & 700 & & & & 1.00 & 1.10 \\
\hline & & EtOH & 640 & & 1144 & & 1.00 & 1.23 \\
\hline & & & 750 & & & & 1.00 & 1.27 \\
\hline & & МеОН & 630 & & 832 & & 1.00 & 1.10 \\
\hline & & & 740 & & & & 1.00 & 1.12 \\
\hline
\end{tabular}

${ }^{a}$ For TRYP data is from ref. [7]

Global analysis of the data revealed that, with the exception of TRYP- $\mathrm{NH}_{2}$, the fluorescence decays are well fitted with sums of two exponentials, Eq. 3.

$I(t)=a_{1} e^{-t / \tau_{1}}+a_{2} e^{-t / \tau_{2}}$
The time-resolved data, summarized in Table 3, show, in the different studied solvents, the existence of a shorter fluorescence decay time $\left(\tau_{2}\right)$, found in the 7-65 ps range, together with a long-lived component $\left(\tau_{1}\right)$, in the $68-499 \mathrm{ps}$ range, (Figure SI19-21 in SI). The data revealed that, while, with TRYP [7] a rising component (negative pre-exponential 


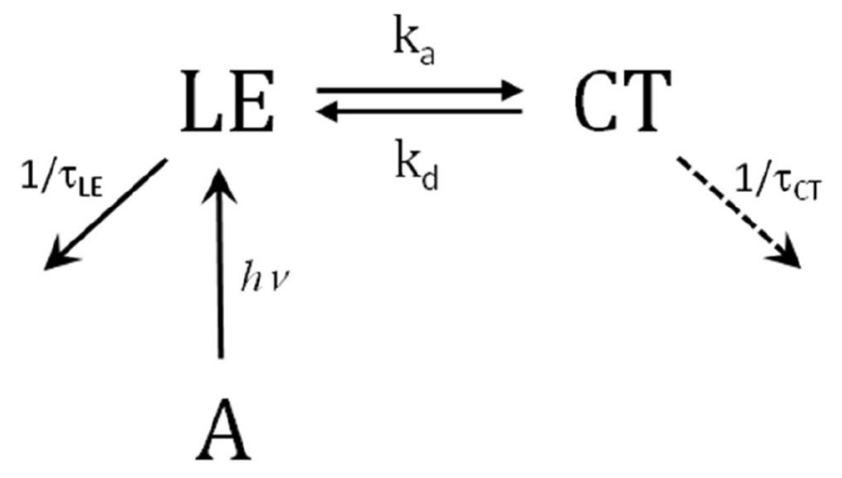

\section{$\mathbf{A}=$ TRYP-2Br, TRYP-4Br, TRYP-I}

Scheme 3 Kinetic scheme for the excited behaviour of TRYP-2Br, TRYP-4Br and TRYP-I in $\mathrm{S}_{1}$

value) is observed when the decays are collected at the longer wavelength emission in polar protic solvents, which was attributed to the formation, in the excited state, of a charge transfer (CT) at the expenses of a locally excited (LE) species (see Scheme 3), for the presently studied tryptanthrin derivatives, despite the double exponential nature of the decays, the presence of a rising component is only clearly observed for TRYP-4Br in MeOH (Table 3).

The data reveal that while, the decay time associated to the $\mathrm{CT}$ species (longer component, $\tau_{1}$ ) decreases with number of $\mathrm{Br}$ atoms and from $\mathrm{Br}$ to $\mathrm{I}$, reflecting the inductive effect of the halogen atoms, the shorter decay component, associated with the LE species $\left(\tau_{2}\right)$, is less dependent on the substitution and nature of the solvent. The absence of negative pre-exponential values in the fluorescence decays is attributed to a strong overlap of LE and CT band emission. This is also observed for TRYP in acetonitrile (Table 3) [7].
It is worth stressing that, as with TRYP [7], it is also possible to obtain, for tryptanthrin derivatives, the rate constants for the interconversion in the excited state of the two species: formation $\left(\mathrm{k}_{a}\right)$ of the CT at the expenses of the LE and deactivation $\left(\mathrm{k}_{d}\right.$ and $\left.\mathrm{k}_{C T}\right)$ of the $\mathrm{CT}$ and $\mathrm{LE}\left(\mathrm{k}_{\mathrm{LE}}=1 / \tau_{\mathrm{LE}}\right)$ species (see Table 4).

In Table 4 , the $\lambda_{\mathrm{i}}$ values are the reciprocal decay times of the shorter $\left(\lambda_{2}=1 / \tau_{2}\right)$ and of the longer $\left(\lambda_{1}=1 / \tau_{1}\right)$ species and are related to the rate constants in Scheme 3. The complete set of equations for the determination of the $\mathrm{k}_{a}, \mathrm{k}_{d}, \mathrm{k}_{L E}$ (which is assumed to have the value for a model compound, indigo, with a value of $152 \mathrm{ps}$ [10]) and $\mathrm{k}_{\mathrm{CT}}$ can be found in ref. [7] and these depends on the $\lambda$ values and normalized pre-exponential factors at the shortest emission wavelength (which is related to the $A$ value $\left(=\mathrm{a}_{12} / \mathrm{a}_{11}\right)$ in Table 4 .

Despite the fact that the $\mathrm{k}_{a}$ rate constant have values of $\sim 10^{10}-10^{11} \mathrm{~s}^{-1}$ (values typically associated to charge transfer mechanisms) they are found to increase with the number (bromine) and atomic number (bromine to iodine), thus indicating a dominance of the ISC to the overall decay of the LE species (Table 4). The reversibility rate constant $\mathrm{k}_{d}$ remains approximately constant with the substitution whereas the $k_{C T}$ values increase in the order TRYP$2 \mathrm{Br}>\mathrm{TRYP}-4 \mathrm{Br}>\mathrm{TRYP}-\mathrm{I}$, again in agreement with the more radiationless nature of the CT species [7].

In contrast with TRYP and the other tryptanthrin analogues, TRYP- $\mathrm{NH}_{2}$ shows single-exponential decays in all solvents, with longer fluorescence lifetime values that vary from $0.8 \mathrm{~ns}$ to $\sim 3.0 \mathrm{~ns}$ (Table 3). Moreover, the strong solvent polarity dependence (Fig. 1, Table 2) is likely to be associated to the emission of the CT state, indicating that upon photoexcitation, a very fast charge transfer occurs, faster than 1 ps (the time resolution of our ps-TCSPC setup), leading to the formation, and subsequent decay, of the relaxed CT state, but now in a ns time range, which contrasts with the other compounds (Table 3).
Table 4 Time-resolved data $\left(\lambda_{1}\right.$, $\lambda_{2}$ and $\left.\mathrm{A}\right)$ and rate constants $\left(k_{a}, k_{d}\right.$ and $\left.k_{\mathrm{CT}}\right)$ recovered the kinetic analysis resulting from Scheme 3

\begin{tabular}{llrrrrrr}
\hline Compound & Solvent & \multicolumn{1}{l}{$\lambda_{1}$} & \multicolumn{1}{c}{$\lambda_{2}$} & \multicolumn{1}{c}{$\mathrm{A}$} & $k_{a}\left(\mathrm{~ns}^{-1}\right)$ & $k_{d}\left(\mathrm{~ns}^{-1}\right)$ & $k_{\mathrm{CT}}\left(\mathrm{ns}^{-1}\right)$ \\
\hline TRYP $^{a}$ & EtOH & 3.92 & 43.14 & 3.55 & 27.93 & 9.45 & 3.10 \\
& $\mathrm{MeOH}$ & 7.85 & 59.27 & 2.70 & 38.81 & 13.43 & 8.30 \\
$\mathrm{TRYP}-2 \mathrm{Br}$ & $\mathrm{EtOH}$ & 5.18 & 83.42 & 8.75 & 68.82 & 8.18 & 5.01 \\
& $\mathrm{MeOH}$ & 5.76 & 83.42 & 6.25 & 66.12 & 10.85 & 5.63 \\
$\mathrm{TRYP}-4 \mathrm{Br}$ & $\mathrm{EtOH}$ & 11.21 & 86.63 & 10.63 & 73.56 & 6.08 & 11.61 \\
& $\mathrm{MeOH}$ & 14.72 & 102.38 & 7.40 & 85.37 & 9.44 & 15.72 \\
TRYP-I & EtOH & 25.31 & 118.54 & 15.88 & 106.44 & 4.55 & 26.28 \\
& $\mathrm{MeOH}$ & 24.48 & 77.66 & 1.94 & 52.97 & 11.99 & 30.60 \\
\hline
\end{tabular}

${ }^{a}$ For TRYP data is from ref [7] 


\section{Conclusions}

A green chemistry procedure with microwave irradiation of indigo dyes allowed the synthesis of tryptanthrin derivatives with two and four bromine atoms, allowing the decrease of the E-factor to less than a half. Mono-substituted amine and iodine tryptanthrin derivatives were obtained, at room temperature, in a straightforward procedure from isatin and isatoic anhydride. The photophysical study showed that, with exception of TRYP-NH $\mathrm{N}_{2}$, the main excited state deactivation pathway is, for all the halogenated-tryptanthrin, intersystem crossing to the triplet state with highly efficient sensitization of singlet molecular oxygen, with yields, $\phi_{\Delta}$ values higher than $80 \%$.

Supplementary Information The online version contains supplementary material available at https://doi.org/10.1007/s43630-021-00117-8.

Acknowledgements This work was supported by Project "Hylight" (no. 031625) 02/SAICT/2017, PTDC/QUI-QFI/31625/2017, which is funded by the Portuguese Science Foundation (FCT) and Compete Centro 2020. The Coimbra Chemistry Centre (CQC) is supported by FCT, through Projects UIDB/00313/2020, and UIDP/00313/2020. We acknowledge the UC-NMR facility for obtaining the NMR data (www. nmrccc.uc.pt).

\section{Declarations}

Conflict of interest The authors declare that there is no conflict to interest.

\section{References}

1. Jahng, Y. (2013). Progress in the studies on tryptanthrin, an alkaloid of history. Archives of Pharmacal Research, 36(5), 517-535. https://doi.org/10.1007/s12272-013-0091-9

2. Tucker, A. M., \& Grundt, P. (2012). The chemistry of tryptanthrin and its derivatives. ARKIVOC, 1, 546-569. https://doi.org/ 10.1002/chin.201243254

3. Jao, C.-W., Lin, W.-C., Wu, Y.-T., \& Wu, P.-L. (2008). Isolation, structure elucidation, and synthesis of cytotoxic tryptanthrin analogues from Phaius mishmensis. Journal of Natural Products, 71(7), 1275-1279. https://doi.org/10.1021/np800064w

4. Hashimoto, T., Aga, H., Chaen, H., Fukuda, S., \& Kurimoto, M. (1999). Isolation and Identification of Anti-Helicobacter Pylori Compounds from Polygonum Tinctorium Lour. Journal of Natural Medicines, 53(1), 27-31.

5. Rasmussen, L. E., Lee, T. D., Daves, J., \& Schmidt, M. J. (1993). Female-to-male sex pheromones of low volatility in the Asian elephant Elephas Maximus. Journal of Chemistry Ecology, 19(10), 2115-2128. https://doi.org/10.1007/BF00979651

6. Honda, G., Tosirisuk, V., \& Tabata, M. (1980). Isolation of an antidermatophytic, tryptanthrin, from indigo plants, polygonum tinctorium and isatis tinctoria. Planta Medica, 38(03), 275-276. https://doi.org/10.1055/s-2008-1074877

7. Pinheiro, D., Pineiro, M., Pina, J., Brandão, P., Galvão, A. M., \& Seixas de Melo, J. S. (2020). Tryptanthrin from indigo: synthesis, excited state deactivation routes and efficient singlet oxygen sensitization. Dyes Pigments, 175, 108125. https://doi.org/10. 1016/j.dyepig.2019.108125

8. Seixas de Melo, J. S. (2020). The molecules of colour and art. molecules with history and modern applications. In A. Albini \& S. Prodi (Eds.), Photochemistry (Vol. 47, pp. 196-216). The Royal Society of Chemistry.

9. Seixas de Melo, J. S. (2018). The molecules of colour. In A. Albini, E. Fasani, \& S. Protti (Eds.), Photochemistry (pp. 68-100). The Royal Society of Chemistry.

10. Pina, J., Sarmento, D., Accoto, M., Gentili, P. L., Vaccaro, L., Galvão, A. M., \& Seixas de Melo, J. S. (2017). Excited-state proton transfer in Indigo. Journal of Physical Chemistry B, 121(10), 2308-2318. https://doi.org/10.1021/acs.jpcb.6b11020

11. Seixas de Melo, J. S., Rondão, R., Burrows, H. D., Melo, M. J., Navaratnam, S., Edge, R., \& Voss, G. (2006). Spectral and photophysical studies of substituted indigo derivatives in their keto forms. ChemPhysChem, 7(11), 2303-2311. https://doi.org/ 10.1002/cphc. 200600203

12. Onambele, L. A., Riepl, H., Fischer, R., Pradel, G., Prokop, A., \& Aminake, M. N. (2015). Synthesis and evaluation of the antiplasmodial activity of tryptanthrin derivatives. International Journal for Parasitology: Drugs and Drug Resistance, 5(2), 48-57. https:// doi.org/10.1016/j.ijpddr.2015.03.002

13. Hwang, J.-M., Oh, T., Kaneko, T., Upton, A. M., Franzblau, S. G., Ma, Z., Cho, S.-N., \& Kim, P. (2013). Design, synthesis, and structure-activity relationship studies of tryptanthrins as antitubercular agents. Journal of Natural Products, 76(3), 354-367. https://doi.org/10.1021/np3007167

14. Kawakami, J., Kakinami, H., Matsushima, N., Nakane, A., Kitahara, H., Nagaki, M., \& Ito, S. (2013). Structure-activity relationship analysis for antimicrobial activities of tryptanthrin derivatives using quantum chemical calculations. Journal of Computer Chemistry Japan, 12(2), 109-112. https://doi.org/10.2477/jccj. 2012-0026

15. Kawakami, J., Matsushima, N., Ogawa, Y., Kakinami, H., Nakane, A., Kitahara, H., Nagaki, M., \& Ito, S. (2011). Antibacterial and antifungal activities of tryptanthrin derivatives. Transactions of the Materials Research Society of Japan, 36(4), 603-606. https:// doi.org/10.14723/tmrsj.36.603

16. Bandekar, P. P., Roopnarine, K. A., Parekh, V. J., Mitchell, T. R., Novak, M. J., \& Sinden, R. R. (2010). Antimicrobial activity of tryptanthrins in Escherichia coli. Journal of Medicinal Chemistry, 53(9), 3558-3565. https://doi.org/10.1021/jm901847f

17. Bhattacharjee, A. K., Hartell, M. G., Nichols, D. A., Hicks, R. P., Stanton, B., van Hamont, J. E., \& Milhous, W. K. (2004). Structure-activity relationship study of antimalarial indolo [2,1-b] quinazoline-6,12-diones (tryptanthrins) three dimensional pharmacophore modeling and identification of new antimalarial candidates. European Journal of Medicinal Chemistry, 39(1), 59-67. https://doi.org/10.1016/j.ejmech.2003.10.004

18. Bhattacharjee, A. K., Skanchy, D. J., Jennings, B., Hudson, T. H., Brendle, J. J., \& Werbovetz, K. A. (2002). Analysis of stereoelectronic properties, mechanism of action and pharmacophore of synthetic Indolo[2,1-b]quinazoline-6,12-dione derivatives in relation to antileishmanial activity using quantum chemical, cyclic voltammetry and 3-D-QSAR CATALYST procedures. Bioorganic and Medicinal Chemistry, 10(6), 1979-1989. https://doi.org/10. 1016/S0968-0896(02)00013-5

19. Patil, S., Mane, A., \& Dhongade-Desai, S. (2018). Ultrasound assisted synthesis of tryptanthrins catalyzed by zinc oxide nanoparticles. Chemistry Science Review Letter, 7(27), 732-740.

20. Catanzaro, E., Betari, N., Arencibia, J. M., Montanari, S., Sissi, C., De Simone, A., Vassura, I., Santini, A., Andrisano, V., Tumiatti, V., De Vivo, M., Krysko, D. V., Rocchi, M. B. L., Fimognari, C., \& Milelli, A. (2020). Targeting topoisomerase II with tryptanthrin derivatives: discovery of 7-((2-(dimethylamino)ethyl)amino) 
indolo[2,1-b]quinazoline-6,12-dione as an antiproliferative agent and to treat cancer. European Journal of Medicinal Chemistry, 202, 112504. https://doi.org/10.1016/j.ejmech.2020.112504

21. Hao, Y., Guo, J., Wang, Z., Liu, Y., Li, Y., Ma, D., \& Wang, Q. (2020). Discovery of tryptanthrins as novel antiviral and antiphytopathogenic-fungus agents. Journal of Agriculture and Food Chemistry, 68(20), 5586-5595. https://doi.org/10.1021/acs.jafc. 0c02101

22. Li, Y., Zhang, S., Wang, R., Cui, M., Liu, W., Yang, Q., \& Kuang, C. (2020). Synthesis of novel tryptanthrin derivatives as dual inhibitors of indoleamine 2,3-dioxygenase 1 and tryptophan 2,3-dioxygenase. Bioorganic and Medicinal Chemistry Letters, 30(11), 127159. https://doi.org/10.1016/j.bmcl.2020.127159

23. Wang, D., Xiao, F., Zhang, F., Huang, H., \& Deng, G.-J. (2020). Copper-catalyzed aerobic oxidative ring expansion of isatins: a facile entry to isoquinolino-fused quinazolinones. Chinese Journal of Chemistry. https://doi.org/10.1002/cjoc.202000368

24. Deryabin, P. I., Moskovkina, T. V., Shevchenko, L. S., \& Kalinovskii, A. I. (2017). Synthesis and antimicrobial activity of tryptanthrin adducts with ketones. Russian Journal of Organic Chemistry, 53(3), 418-422. https://doi.org/10.1134/s107042801 7030174

25. Kaur, R., Manjal, S. K., Rawal, R. K., \& Kumar, K. (2017). Recent synthetic and medicinal perspectives of tryptanthrin. Bioorganic \& Medicinal Chemistry, 25(17), 4533-4552. https://doi.org/10. 1016/j.bmc.2017.07.003

26. Krivogorsky, B., Nelson, A. C., Douglas, K. A., \& Grundt, P. (2013). Tryptanthrin derivatives as toxoplasma gondii Inhibitorsstructure-activity-relationship of the 6-position. Bioorganic and Medicinal Chemistry Letters, 23(4), 1032-1035. https://doi.org/ 10.1016/j.bmcl.2012.12.024

27. Sriraman, K., Novak, M. J., Baum, J. C., Herron, A., \& Olson, J. A. (2013). Surface behavior and imaging of the lowest unoccupied molecular orbital of Indolo[2,1-b]quinazoline-6,12-dione (tryptanthrin) via scanning tunneling microscopy. Surface Science, 616, 110-114. https://doi.org/10.1016/j.susc.2013.06.010

28. Liang, J. L., Park, S.-E., Kwon, Y., \& Jahng, Y. (2012). Synthesis of benzo-annulated tryptanthrins and their biological properties. Bioorganic and Medicinal Chemistry, 20(16), 4962-4967. https:// doi.org/10.1016/j.bmc.2012.06.034

29. Novak, M. J., Clayton Baum, J., Buhrow, J. W., \& Olson, J. A. (2006). Scanning tunneling microscopy of indolo[2,1-b]quinazolin-6,12-dione (tryptanthrin) on HOPG: evidence of adsorptioninduced stereoisomerization. Surface Science, 600(20), L269L273. https://doi.org/10.1016/j.susc.2006.07.036

30. Pinheiro, D., Pineiro, M., \& Seixas de Melo, J. S. (2021). Sulfonated tryptanthrin anolyte increases performance in $\mathrm{pH}$ neutral aqueous redox flow batteries. Communications Chemistry, 4(1), 89. https://doi.org/10.1038/s42004-021-00523-0

31. Fang, Y.-P., Lin, Y.-K., Su, Y.-H., \& Fang, J.-Y. (2011). Tryptanthrin-loaded nanoparticles for delivery into cultured human breast cancer cells, MCF7: the effects of solid lipid/liquid lipid ratios in the inner core. Chemical and Pharmaceutical Bulletin, 59(2), 266-271. https://doi.org/10.1248/cpb.59.266

32. Kawakami, J., Osanai, C., \& Ito, S. (2020). Photophysical properties of 2-hydroxytryptanthrin analog as a near-infrared dye for fluorescent imaging. Transactions of the Materials Research Society of Japan, 45(1), 19-22. https://doi.org/10.14723/tmrsj.45.19

33. Kawakami, J., Sasagawa, M., \& Ito, S. (2018). 2-Hydroxy-1((2-(pyridin-2-yl)hydrazono)methyl)tryptanthrin as a Fluorescent Chemosensor for Metal Ions. Transactions of the Materials Research Society of Japan, 43(3), 209-212.https://doi.org/10. 14723/tmrsj.43.209

34. Kawakami, J., Kinami, Y., Takahashi, M., \& Ito, S. (2018). 2-Hydroxytryptanthrin and 1-Formyl-2-hydroxytryptanthrin as fluorescent metal-ion sensors and near-infrared fluorescent labeling reagents. Transactions of the Materials Research Society of Japan, 43(2), 109-112. https://doi.org/10.14723/tmrsj.43.109

35. Kawakami, J., Tsuiki, A., Ito, S., \& Kitahara, H. (2016). Naphthalene ring-fused 2-aminotryptanthrin as a fluorescent chemosensor for $\mathrm{Al}^{3+}$. Transactions of the Materials Research Society of Japan, 41(1), 131-133. https://doi.org/10.14723/tmrsj.41.131

36. Kawakami, J., Takahashi, M., Ito, S., \& Kitahara, H. (2016). Photophysical properties of the 2-hydroxytryptanthrin and its sodium salt as near-infrared dyes for fluorescent imaging. Analytical Sciences Japan, 32(2), 251-253. https://doi.org/10.2116/analsci.32. 251

37. Kawakami, J., Soma, A., Kikuchi, K., Kikuchi, Y., Ito, S., \& Kitahara, H. (2014). 2-Aminotryptanthrin derivative with pyrene as a FRET-based fluorescent chemosensor for metal ions. Analytical Sciences Japan, 30(10), 949-954. https://doi.org/10.2116/anals ci.30.949

38. Kawakami, J., Kikuchi, K., Chiba, K., Matsushima, N., Yamaya, A., Ito, S., Nagaki, M., \& Kitahara, H. (2009). 2-Aminotryptanthrin derivative with pyrene as a FRET-based fluorescent chemosensor for $\mathrm{Al}^{3+}$. Analytical Sciences Japan, 25(12), 1385-1386. https://doi.org/10.2116/analsci.25.1385

39. Brandão, P., Pinheiro, D., Seixas de Melo, J. S., \& Pineiro, M. (2020). I2/NaH/DMF as Oxidant trio for the synthesis of tryptanthrin from indigo or isatin. Dyes Pigments, 173, 107935. https:// doi.org/10.1016/j.dyepig.2019.107935

40. Dubois, J. T., \& Wilkinson, F. (1963). Radiative lifetime of triplet biacetyl. The Journal of Chemical Physics, 39(4), 899-901. https://doi.org/10.1063/1.1734389

41. Montalti, M., Credi, A., Prodi, L., \& Gandolfi, M. T. (2006). Handbook of photochemistry 3rd (Edition). Taylor \& Francis Group.

42. Seixas de Melo, J. S., Pina, J., Dias, F. B., \& Maçanita, A. L. (2013). Experimental techniques for excited state characterisation. In H. D. Burows (Ed.), Applied Photochemistry (pp. 533-585). Springer.

43. Martínez, C. G., Neuner, A., Martí, C., Nonell, S., Braun, A. M., \& Oliveros, E. (2003). Effect of the media on the quantum yield of singlet oxygen $\left(\mathrm{O}_{2}\left({ }^{1} \Delta \mathrm{g}\right)\right)$ production by $9 \mathrm{H}$-Fluoren-9-one: solvents and solvent mixtures. Helvetica Chimica Acta, 86(2), 384-397. https://doi.org/10.1002/hlca.200390039

44. Pina, J., Seixas de Melo, J. S., Burrows, H. D., Maçanita, A. L., Galbrecht, F., Bünnagel, T., \& Scherf, U. (2009). Alternating binaphthyl-thiophene copolymers: synthesis, spectroscopy, and photophysics and their relevance to the question of energy migration versus conformational relaxation. Macromolecules, 42(5), 1710-1719. https://doi.org/10.1021/ma802395c

45. Striker, G., Subramaniam, V., Seidel, C. A. M., \& Volkmer, A. (1999). Photochromicity and fluorescence lifetimes of green fluorescent protein. The Journal of Physical Chemistry B, 103(40), 8612-8617. https://doi.org/10.1021/jp991425e

46. Seixas de Melo, J. S., \& Barroso, M. (2001). Síntese, espectroscopia e tingimento com corantes: O Índigo. Boletim da Sociedade Portuguesa da Química, 81, 66-69.

47. Gaboriaud-Kolar, N., Nam, S., \& Skaltsounis, A.-L. (2014). Progress in the chemistry of organic natural products. In H. Falk, A. Kinghorn, \& J. Kobayashi (Eds.), A colourful history: the evolution of indigoids. Springer.

48. Sheldon, R. A. (2017). The E factor 25 years on: the rise of green chemistry and sustainability. Green Chemistry, 19(1), 18-43. https://doi.org/10.1039/C6GC02157C

49. Kawakami, J., Kawaguchi, H., Kikuchi, K., Yamaya, A., Ito, S., \& Kitahara, H. (2013). Fluorescent solvatochromism of 2-aminotryptanthrin. Transactions of the Materials Research Society of Japan, 38(1), 123-125. https://doi.org/10.14723/tmrsj.38.123

50. Kawakami, J., Osanai, C., \& Ito, S. (2018). Fluorescence emission mechanism of three $\mathrm{N}, \mathrm{N}$-dimethylaminotryptanthrins by density 
functional theory calculations. Transactions of the Materials Research Society of Japan, 43(5), 319-323. https://doi.org/10. $14723 / \mathrm{tmrsj} .43 .319$

51. Kawakami, J., Kadowaki, T., Ikeda, M., Habata, Y., Ito, S., \& Kitahara, H. (2016). Spectral characteristics of highly fluorescent 2-( $N, N$-dimethylamino)tryptanthrin. Transactions of the Materials Research Society of Japan, 41(2), 143-146. https://doi.org/10. $14723 /$ tmrsj.41.143

52. Seixas de Melo, J. S., \& Fernandes, P. F. (2001). Spectroscopy and photophysics of 4- and 7-hydroxycoumarins and their thione analogs. Journal of Molecular Structure, 565-566, 69-78. https:// doi.org/10.1016/S0022-2860(01)00458-6
53. El-Sayed, M. A. (1968). Triplet state-its radiative and nonradiative properties. Accounts of Chemical Research, 1(1), 8-16. https:// doi.org/10.1021/ar50001a002

54. Dang, H., Hou, X., Roos, P., \& Nielsen, S. P. (2013). Release of iodine from organic matter in natural water by $\mathrm{K}_{2} \mathrm{~S}_{2} \mathrm{O}_{8}$ oxidation for ${ }^{129}$ I determination. Analytical Methods, 5(2), 449-456. https:// doi.org/10.1039/C2AY25958C

55. Hacobian, S., \& Iredale, T. (1950). Role of oxygen in the photolysis of iodides. Nature, 166(4212), 156-157. https://doi.org/ $10.1038 / 166156 b 0$ 